\title{
A SEMIÓTICA TENSIVA: UMA TEORIA IMANENTE DO AFETO
}

\section{TENSIVE SEMIOTICS: AN IMMANENT THEORY OF AFFECTION}

WALDIR BEIVIDAS *

RESUMO: Este texto avança reflexões que buscam defender a hipótese de uma epistemologia do conhecimento humano, nomeada epistemologia discursiva. De estatuto imanente à linguagem, vem sendo preparada para rivalizar com a epistemologia das ciências naturais, via de regra realista, e com a epistemologia das filosofias, mormente transcendental. 0 texto é o quarto de um concerto de ideias, cujos três primeiros movimentos foram publicados, ou estão em vias de publicação, todos a procurar fundamentar tal epistemologia. Nascida da proposição do princípio do arbitrário e da Semiologia dele derivada, por F. Saussure, primeiro movimento, foi balizada pelo princípio da imanência da teoria da linguagem de L. Hjelmslev, segundo movimento, e edificada pelas proposições de A. J. Greimas em sua teoria semiótica, terceiro movimento. Seu progresso e eficácia heurística podem ser atestados na teoria da semiótica tensiva de $\mathrm{Cl}$. Zilberberg, justamente porque avança um conhecimento sobre a região que mais desafia a imanência: a região do afeto, da sensibilidade. Geralmente tida por indócil à formalização, à estrutura, tal região é suposta como transcendente a uma gra-

* Docente da USP - Universidade de São Paulo. E-mail: waldirbeividas@usp.br. 
mática imanente do afeto. A semiótica tensiva de Zilberberg, integralmente subordinada à tradição linguística e ao princípio da imanência hjelmsleviana e greimasiana, ilustra a governança dessa epistemologia discursiva.

PALAVRAS-CHAVE: Semiótica. Imanência. Transcendência. Afeto. Epistemologia. Realidade.

ABSTRACT: This article puts forth some reflections that defend the hypothesis of an immanent epistemology of human knowledge, named as discursive epistemology. Its immanent status rivals the often realist epistemology of natural sciences, as well as that of transcendental philosophies. This text is the fourth in a concert of ideas, whose first three installments are already published, or in the way of being published. All of them strive to justify such discursive epistemology. The first one discusses the immanent epistemology born from F. Saussure's principle of arbitrary and the Semiology that arose from it. It was then delineated by the principle of immanence developed by L. Hjelmslev's language theory, dealt with in our second act. The third movement shows the further development proposed by A. J. Greimas in his Semiotic theory. The progress of immanent theory and its heuristic effectiveness can be attested in C. Zilberberg's Tensive Semiotic theory precisely because it advances knowledge on the area thatmostchallenges immanence: the area of affection and sensibility. This area is generally understood to be resistant to formalization and structure. It is seen as transcendent to an immanent grammar of affection. Zilberberg's Tensive Semiotic, in full accord with linguistic tradition and the hjelmslevian and greimasian principles of immanence, illustrates the governance of this discursive epistemology. 
KEYWORDS: Semiotics. Immanence. Transcendence. Affection. Discursive epistemology. Reality.

\section{Introdução}

Pelo ato semiológico que se dá por arbitrariedade radical do signo ficou prenunciado em Saussure um estatuto imanente ao mundo. Por ele, o referente se internaliza, adentra a linguagem e é o único a nos servir de comunicação, mais que isso, de percepção e de cognição do mundo. Fora da linguagem o mundo não há. Toda intuição ou entendimento sobre algo a haver já se implica desse signo, qual seja, do arbitrário de raiz, das linguagens. Foi o que procurei demonstrar em Beividas (2015a).

Por sua vez, com Hjelmslev o conceito de imanência se instaurou, se legitimou e se radicalizou na esfera metodológica da teoria da linguagem, de uma linguística-linguística que construísse a sua conceptualidade tão apenas de suas próprias entranhas, imanentes. Mais que isso, com o mesmo Hjelmslev, a imanência não parou aí, galgou um patamar acima: extrapolou a metodologia de construção conceptual e ganhou o estatuto maiúsculo de uma verdadeira Epistemologia para o conhecimento humano, hipotecada que ficou a linguagem no epicentro, como "a forma de conceber o mundo" (HJELMSLEV, 1971b, p. 173). Proposições de Hjelmslev, como esta última, são teses maximais da imanência do mundo, gerido pela imanência da linguagem, única forma pela qual o concebemos. As teses hjelmslevianas foram detidamente examinadas em Beividas (2013 e 2015b).

Em seguida, no desenvolvimento de sua teoria semiótica, de inspiração diretamente hjelmsleviana, o conceito de 
forma (imanente) ganhou deiscência tríplice, em Greimas: forma linguística, forma semiótica e forma científica. A proposta foi construída para homogeneizar epistemologicamente, como macrolinguagem global, as ciências da natureza e as ciências do homem, assimilando o universo das ciências ao universo semântico das linguagens. Com a proposição greimasiana assim disposta, tendo por lastro o percurso de Saussure até ela, via Hjelmslev, entendo como não temerário continuar a perseguir o intento de justificar a hipótese ampla de uma Epistemologia do conhecimento integralmente imanente à linguagem, a que venho chamando epistemologia discursiva (cf. BEIVIDAS, 2008, 2014 e 2017).

Por razões de coerência e de continuidade da proposição dessa hipótese, o presente texto está dedicado e homenageia o pensamento de Claude Zilberberg. Quero evidenciar que este autor aciona uma teoria tensiva em que o conceito de imanência avança até os limites máximos onde, por assim dizer, a substância mais resiste à forma. Para além do regime categorial, das oposições binárias ou em quadratura, em que a teoria semiótica de Greimas provou a eficiência de uma metodologia imanente à linguagem, na descrição e interpretação dos mais variados textos, verbais ou não; para além do valor das pesquisas atuais em semiótica, que expandiram o texto para o contexto, para o intertexto, interdiscursividades, para as práticas humanas de produção significante (Fontanille e outros) e até para as práticas experienciais das situações intersubjetivas da própria vida humana (Landowski e outros); para além disso, a semiótica tensiva de Zilberberg apruma a proa e zarpa para um novo oceano de navegação, preservando a continuidade do horizonte teórico, bússola imanente à mão, que vai da linguística saussuriana e hjelmsleviana, até a semiótica greimasiana, dando-lhes sequência e coerência: o mar 
da fenomenologia do afeto.

A presença de Zilberberg no concerto de estudos sobre a hipótese de uma epistemologia discursiva imanente, em continuidade ao desenvolvimento dos demais textos, significa uma espécie de concerto andante em quatro movimentos. $\mathrm{Ou}$ então, se me fosse lícita ainda outra metáfora, desta feita cosmogônica, significa o completamento dos quatro elementos telúricos de sua força: à terra, em que se semeou a semente arbitrária da Semiologia, por Saussure; ao fogo, em que a imanência ganhou toda a energia "tética" (do grego thetikós = relativo a tese), em Hjelmslev; à água que tudo temperou com as propostas epistemológicas de macrolinguagem para o universo científico, em Greimas, a esses elementos telúricos se soma o ar da teoria tensiva de Zilberberg que vem dar o fôlego necessário à continuidade de operação do conceito de imanência na busca contínua da inteligibilidade semiótica do mundo humano.

No entanto, para melhor se aquilatar o valor das proposições tensivas de Zilberberg e estimar a manutenção do princípio de imanência nos alicerces de seu edifício teórico, temos antes de ajustar o foco sobre o conceito de imanência no próprio âmbito da teoria semiótica. Farei uma breve incursão sobre como esse conceito se dispõe no imaginário dos semioticistas eles próprios. A ampliação do alcance da imanência, do nível metodológico para o nível epistemológico, como aqui pretendo, pede um posicionamento e discernimento perante o conceito frente a entendimentos por vezes dissonantes, contraditórios, conflitantes, no próprio foro interno da semiótica. 


\section{Imanência e pertinência em Jacques Fontanille}

Dentre os pesquisadores do campo semiótico que mais se pronunciam ultimamente no debate sobre a imanência e que, reconheça-se, mais procura conciliar forças antagonistas no interior desse campo, Fontanille nos convida a ver uma espécie de evolução do conceito e adaptação frente à evolução das disciplinas vizinhas com as quais a semiótica dialoga e disputa forças. Do farto e fecundo volume de suas pesquisas gerais em semiótica é suficiente à presente reflexão apenas dois de seus textos: um prefácio ao livro de D. Ablali (2003), e as aberturas das duas versões próximas das suas reflexões em Pratiques sémiotiques (2008a, b).

Em prefácio à tese de doutoramento de D. Ablali (2003, p. 13-28) trabalho em que o autor procura justificar uma mudança de paradigma - a passagem do descontínuo ao contínuo na evolução das pesquisas semióticas desde meados do século passado - Fontanille toma como fio condutor justamente um exame do princípio de imanência. Diante desse princípio, diz o prefaciador, duas são as atitudes que se lhe contrapõem: (i) a dos "contextualistas" - que colocam sob a bandeira do contexto todos os dados julgados externos ao texto e (ii) a dos que eu chamaria de realistas, ou, segundo Fontanille "que preconizam o retorno à 'realidade'” (in ABLALI, 2003, p. 14).

Para abreviar os dados mais concernentes às reflexões de Fontanille em prol do temário aqui em jogo, diria que a primeira contraposição vem de fora, são pressões externas, de teorias outras do discurso e concorrentes à semiótica: a chamada Análise do Discurso, as Análises da Conversação, Semânticas dos Textos e demais teorias textuais, sem que essa série se pretenda exaustiva. Entendem a imanência da 
semiótica como uma limitação (indevida) do campo em foco; noutros termos, partem de uma visada em extensão para a crítica que dirigem à semiótica greimasiana. A segunda contraposição ao princípio de imanência, realista, vem de dentro do foro semiótico, numa visada em intensão. Questiona não apenas a restrição metodológica, mas também por assim dizer uma suposta camisa de força epistemológica do conceito, por fazê-lo se comprimir num "leito de Procusto" segundo acusação de J. C. Coquet (cf. adiante).

É esta segunda contraposição que mais nos desafia aqui. Isto porque a primeira, a dos contextualistas, como diz Fontanille, eles já se sentem previamente "imunizados" contra qualquer suspeita de idealismos ou solipsismos "ipso facto pelo simples apelo ao contexto" (in ABLALI, 2003, p. 14). Com efeito, quando se agregam às análises de um texto dados provindos de todos os lados, do contexto, da história, da biografia do autor, de seu corpo, de seu caráter, de seu psiquismo, da cultura ambiente, enfim de qualquer adjacência ao objeto examinado; quando não se têm a preocupação ou antes não se cobram e nenhuma outra teoria lhes cobra o senso aguçado do conceito de pertinência, então tudo vale, tudo orna a análise de procedimentos retóricos e estilísticos sedutores, nada mais é exigido e assim a análise se torna por assim dizer mais confortável.

Já a segunda contraposição é mais grave. Trata-se da crítica à coerção epistemológica do princípio da imanência; trata-se das dificuldades "e notadamente das complexidades e das perplexidades, diz Fontanille, que o semioticista 'imanentista' tem de afrontar quando é levado a precisar sua concepção do 'referente' e da 'realidade'". Nesta contraposição põe-se em cheque o princípio da imanência ele próprio perante a reivindicação da realidade. Fontanille encontra três 
subgrupos de pesquisas que buscam "interrogar o próprio estatuto de realidade da linguagem e as condições que permitem atribuir-lhe o estatuto de um 'real'". Convém reproduzir em extenso a sequência do seu raciocínio:

Para uns (Milner, Achard), com certas feições lacanianas, no que ela tem de mais inacessível e de mais virtual é a própria língua que seria o próprio "real". Para outros (Petitot), é a conformidade dos modelos às "coisas-mesmas" que permite à teoria manter o contato com a realidade; nesse sentido, a semiótica poderia se tornar um ramo das ciências da natureza (a physique du sens ou sémio-physique), conforme expressão proposta pelo próprio R. Thom, e pretender assim o mesmo tipo de realismo que estas últimas. Para outros, enfim (Benveniste, Coquet), é o acionamento da língua, o fato mesmo de praticar a linguagem, que lhe confere um estatuto de realidade; é o ato (de enunciação) que nos faz entrar na linguagem e ao mesmo tempo e no mesmo movimento, entrar em contato com a realidade; então, a realidade é onde estamos mergulhados diretamente pelo exercício da faculdade de linguagem. (in ABLALI, 2003, p. 14, tradução nossa) ${ }^{1}$.

A longa citação vem-nos servir de primeira ilustração sobre os vários modos como circula a discussão sobre a imanência no campo semiótico, no presente caso, a imanência

1 "Pour les uns (Milner, Achard), avec quelques accents lacaniens, c'est la langue même dans ce qu'elle a de plus inaccessible et de plus virtuel, qui serait le 'réel' même. Pour d'autres (Petitot), c'est la conformité des modèles aux 'choses mêmes' qui permet à la théorie de maintenir le contact avec la réalité ; en ce sens, la sémiotique pourrait devenir une branche des sciences de la nature (la physique du sens, ou sémiophysique, selon l'expression proposée par $R$. Thom lui-même) et prétendre ainsi au même type de réalisme que ces dernières. Pour d'autres enfin (Benveniste, Coquet), c'est la mise en fonctionnement de la langue, le fait même de pratiquer le langage qui lui confère un statut de réalité; c'est l'acte (d'énonciation) qui nous fait, en même temps et dans le même mouvement, entrer dans le langage et entrer en contact avec la réalité ; dès lors, la réalité est ce dans quoi nous baignons directement par l'exercice de la faculté de langage". 
frente à realidade. Sem querer cobrar de César o que não lhe cabe no exercício de um pequeno prefácio, vê-se claramente acima que a leitura de Fontanille, sobre as pesquisas dos autores convocados, levanta a questão do estatuto de realidade a ser conferido à linguagem. É como se o estatuto imanente da linguagem lhe ameaçasse algum grau de realidade enquanto existente. Ora, para situar a presente reflexão frente a esse modo de discussão sobre a imanência, teria a dizer que a questão aqui vai na contramão do modo como Fontanille a vê, nesse seu pequeno texto. A questão que desafia-nos aqui não é sobre o estatuto de realidade da linguagem, mas sobre o estatuto (imanente) de linguagem a ser determinado à própria realidade e, portanto, a de legitimar a hipótese de uma epistemologia discursiva derivada desse entendimento ${ }^{2}$.

Um segundo movimento das reflexões de Fontanille em torno do princípio da imanência vem da abertura de seu trabalho sobre Pratiques sémiotiques (2008a, b). Suas primeiras linhas expõem o entendimento que por longo tempo se teve do princípio na semiótica de Greimas. Segundo Fontanille, formulado por Hjelmslev, tal princípio advogava uma limitação da análise ao texto e logo remete-o ao famoso slogan greimasiano "fora do texto não há salvação". Mais ainda, isso fora decorrência da decisão saussuriana de limitar a análise ao sistema da língua. Tratou-se então de uma estratégia descritiva

2 Logo adiante retomarei com mais foco a oposição imanência vs. realidade, pondo em cena algumas das posições de J. C. Coquet perante a imanência. Pelo momento, não cabe adentrar longamente na posição com ares lacanianos de Milner e Achard, cujos textos não são citados por Fontanille. Em todo caso, se este tem razão na sua leitura, a posição daqueles seria a que mais se aproxima dos propósitos da reflexão aqui em jogo. No entanto, minhas próprias pesquisas no campo lacaniano não me permitem tal otimismo (2001, 2009). Via de regra as leituras psicanalíticas dos três registros lacanianos - Imaginário, Simbólico e Real - enfatizam o Real como restrição ao campo do Simbólico (à linguagem), como fora dele, e não como submissão a ele ou como absorção à linguagem, tal como transparece na frase de Fontanille, diga-se de passagem: o que seria quase tudo o que pretendo com a epistemologia discursiva: a linguagem como determinante do único e possível "real" dado ao homem. 
que evitava o canto da Sereia de práticas hermenêuticas sem lastro e se postava como uma "ascese metodológica fecunda" que permitia "levar tão longe quanto possível a pesquisa de modelos necessários a uma análise imanente, e de delimitar o campo de investigação da semiótica do texto e do discurso" (FONTANILLE, 2008a, p. 10).

A sequência da reflexão se encarrega de mostrar como se deu e se deve dar o ultrapassamento da "redução ao texto" quando o semioticista se vê diante de novos objetos, ligados não apenas à semiótica das culturas, da proliferação dos objetos arquitetônicos, urbanos, estratégias de mercado, até mesmo a "degustação de um cigarro ou um vinho" - para citar parte ínfima da Cultura - mas também ligados à semiótica da intersubjetividade nas interações humanas, da vivência experiencial nas situações face a face entre as pessoas, tudo devendo ser integrado no grande guarda-chuva das práticas semióticas humanas. Fontanille chama isso de "transgressões repetidas" a que se obrigam os semioticistas na ampliação do horizonte de suas análises (2008a, p. 10).

Mesmo essa ampliação não prejudica o princípio de imanência, segundo o autor:

Quer seja nos limites do texto ou nas explorações extratextuais, o princípio de imanência revelou grande potencial teórico, pois a restrição que ele impõe à análise é uma das condições necessárias da modelização e, em consequência, do enriquecimento da proposição teórica global: sem o princípio de imanência, não haveria teoria narrativa mas uma simples lógica da ação aplicada a motivos narrativos; sem o princípio de imanência, não haveria teoria das paixões mas simples importação de explicações psicanalíticas; sem o princípio de imanência não haveria semiótica do sensível mas apenas reprodução ou acomodação das análises fenomenológicas [...]. 0 princípio de imanência não é então ape- 
nas um limite imposto ao campo da análise, porque ele coage também o conjunto do procedimento de modelização. (FONTANILLE, 2008a, p. 12, tradução e grifo nossos) ${ }^{3}$.

Ora, o acompanhamento das reflexões de Fontanille desde a abertura desse texto em foco até a última citação mostra claramente que ele, assim como boa parte dos semioticistas ligados a Greimas, tem o imaginário voltado às limitações da imanência, como redução, restrição, enfim, coações da imanência na análise e na teoria. Assim pensado, turvam a meu ver a interpretação forte do conceito de imanência de Hjelmslev e também a do slogan greimasiano.

Com efeito, no linguista de Copenhague a imanência não induz a limitar a análise ao texto, mas se destina a dois grandes objetivos outros.

0 primeiro é edificar a conceptualidade de uma teoria da linguagem apenas do interior dela mesma, isto é, a partir de suas produções textuais ou discursivas. A proposição da imanência para a metodologia construtiva e, em seguida, descritiva, da teoria significou barrar e não deixar-se inundar de conceptualidades provenientes de outras esferas, sobretudo filosóficas e psicológicas para o plano do conteúdo, acústicas e fisiológicas para o plano da expressão. Tratou-se então de uma construção conceptual imanente da teoria e não uma limitação descritiva da análise ao texto. E se, na busca

3 "Que ce soit dans les limites du texte ou dans les explorations extra-textuelles, le principe d'immanence s'est révélé d'une grande puissance théorique, car la restriction qu'il impose à l'analyse est une des conditions nécessaires de la modélisation et, par conséquent, de l'enrichissement de la proposition théorique globale: sans le principe d'immanence, il n'y aurait pas de théorie narrative, mais une simple logique de l'action appliquée à des motifs narratifs ; sans le principe d'immanence, il n'y aurait pas de théorie des passions, mais une simple importation d'explications psychanalytiques; sans le principe d'immanence il n'y aurait pas de sémiotique du sensible, mais seulement une reproduction ou un aménagement des analyses phénoménologiques [...] Le principe d'immanence n'est donc pas seulement une limite imposée au champ de l'analyse, car il contraint aussi l'ensemble de la procédure de modélisation». 
de construir-se internamente, ela necessitava num primeiro momento pôr entre parênteses os dados variáveis da fenomenologia da vida humana, era apenas uma restrição provisória de estratégia tática, subordinada aos princípios de coerência e simplicidade, a ser sanada posteriormente pelo terceiro princípio do empirismo hjelmsleviano, o da exaustividade, com a recuperação por catálise dos dados fenomenológicos (transcendentes), desde que todo o edifício continuasse regulado pela imanência conceptual (HJEMSLEV, 1971a - cf. o capítulo final).

O segundo grande objetivo foi indicado com mais propriedade por F. Bordron em debate ocorrido numa das sessões do Séminaire International de Semiótica que ocorre anualmente em Paris, sessão de 20 de novembro de 2013. Para defender o conceito de imanência perante mordazes críticas de J. C. Coquet (cf. adiante), Bordron resume sintética e acertadamente esse segundo objetivo. Trata-se com o princípio de imanência, segundo ele, de erigir um "plano comum" de análise de objetos heterogêneos. Com efeito, dados como a reivindicação dos contextualistas, dos realistas, a exigência da presença do corpo enunciante, da percepção e tutti quanti, para que possam ser analisados de modo coerente, simples e exaustivamente, devem ser dispostos num plano comum que sirva, na expressão certeira de Bordron, de "princípio de razão suficiente", que funcione como "ordem de razão". É pois uma "exigência de construtibilidade", senão não há "racionalidade semiótica"4.

De modo que podemos deduzir dessas fortes argumentações de Bordron que, sem o critério da imanência, a análise se

4 O áudio dessa conferência foi enviado por Ivan Darrault aos membros do campo semiótico que acompanham anualmente os seminários. Ainda não pude ver tais argumentos de Bordron vertidos em textos publicados. 
torna exercício livre de literatura, cuja maior ou menor felicidade pode servir aqui e acolá de estímulo, mas que não constrói uma disciplina de vocação científica. E podemos igualmente deduzir que, na interpretação de Fontanille, generalizada aos demais semioticistas, a imanência de Hjelmslev acabou por ficar depauperada a uma limitação analítica que não condiz, salvo melhor juízo, com as proposições de Copenhague.

Por sua vez, a mesma turvação parece ocorrer também na leitura que faz Fontanille do slogan greimasiano. "Fora do texto não há salvação" é adágio que não porta ligação direta com o conceito de imanência. Os próprios semioticistas, caímos por vezes na cilada de amarrar o adágio ao conceito. Ora, todas as vezes em que se examinam as reflexões de Greimas em torno das estratégias de descrição, onde insere o adágio, é possível notar que ele o faz sobretudo para alertar quanto à conveniência da atitude de lucidez perante as escolhas descritivas e do critério de pertinência para se alcançar uma descrição tendencialmente mais objetiva e científica e evitar as idiossincrasias hermenêuticas do pesquisador.

É o caso, por exemplo, do contexto da expressão mais veemente e completa com que brindou a "debutância" da semiótica brasileira na conferência de Ribeirão Preto, em 1973. Basta notar, nos derradeiros parágrafos dela, que Greimas ressaltava o ganho que se pode ter na vocação à cientificidade de uma disciplina quando se adota a atitude do extremo respeito ao texto e à sua autonomia perante os seus usuários, enunciador e enunciatário. É dos raros momentos em que tece elogios a um filósofo:

Qual era a preocupação fundamental de Husserl? Para ele o problema consistia em saber como pôr entre parênteses o sujeito da enunciação, condição para ele da possibilidade da ciência [...]. Eis aí a verdadeira problemática, qual seja, se 
nosso conhecimento do mundo advém sempre de um sujeito cognoscente, o que podemos dizer de seguro e correto sobre o mundo, em que condições a ciência é possível. (GREIMAS, 1974 , p. 24-25, tradução nossa) ${ }^{5}$.

É então que se vale do conceito de "redução fenomenológica" do filósofo, operação que nos permite "respirar", diz Greimas, que nos permite colocar o mundo "como objeto" a conhecer. E imediatamente se manifesta sobre o que chama a tendência moderna de reintrodução do sujeito:

Enquanto ele [o sujeito] permanece como sujeito pressuposto [entenda-se: ao texto], tudo bem, mas assim que se passa ao sujeito psicológico, ao sujeito ontológico, ao sujeito transcendental, então vocês abrem a torneira de algo que os ultrapassará. A semiótica será então destruída [...]. Portanto, há limites a não ultrapassar nesse sentido. Por quê? Porque podemos ultrapassar, mas é necessário avaliar o preço que vamos pagar se passamos [...] é preciso que o homem seja lúcido sobre o que faz. (GREIMAS, 1974, p. 25, tradução nossa) ${ }^{6}$.

\section{É nesse contexto de advertência e de pleito de lucidez} que conclui a conferência: "Fora do texto, nenhuma salvação. Todo o texto, nada senão o texto e nada fora do texto." (GREIMAS, 1974, p. 25).

5 "Quelle était la préoccupation fondamentale de Husserl ? Le problème pour lui consistait à savoir comment mettre entre parenthèses le sujet de l'énonciation. Condition pour lui de la possibilité de la science [...] C'est là la vrai problématique, c'est-à-dire, si notre connaissance du monde relève toujours d'un sujet connaissant, qu'est-ce que nous pouvons dire de sûr et certain sur le monde, dans quelles conditions la science est-elle possible.". (GREIMAS, 1974, p. 24-25).

6 “Tant qu'il reste sujet présupposé [entenda-se: ao texto], ça va, mais dès qu'on passe vers le sujet psychologique, le sujet ontologique, le sujet transcendantal, alors vous ouvrez les robinets de quelque chose qui vous dépassera. La sémiotique sera alors détruite [...]. Donc il y a des limites à ne pas dépasser dans ce sens. Pourquoi ? Parce qu'on peut dépasser, mais il faut évaluer le prix qu'on va payer si on passe [...] il faut que l'homme soit lucide de ce qu'il fait." (GREIMAS, 1974, p. 25). 
É o caso também, num segundo exemplo, quando responde a uma questão de H. Parret, por ocasião do Colóquio de Semiótica em Cerisy, em 1983, do por que lhe interessava a figura do cubo de Merleau-Ponty:

Vocês podem olhar por todos os lados, tem cada vez uma aparência diferente, mas o cubo, enquanto tal, permanece idêntico por toda eternidade. Eis uma boa definição do discurso enquanto objeto autônomo - "fora do texto não há salvação"! É uma definição que nos permite falar do discurso independentemente das variáveis que constituem o emissor e o receptor. Há sempre o texto, como o cubo; há a estrutura textual ou narrativa, como uma invariante na qual podem se fundar nossas análises. Não se trata de reduzir essa invariante, como se faz com demasiada frequência, seja ao sujeito da enunciação, seja ao enunciatário. (in ARRIVÉ; COQUET, 1987, p. 311, tradução nossa) ${ }^{7}$.

Nota-se claramente na reflexão greimasiana, em que a máxima se põe, que a imanência não está aí para nada. Tratase apenas de postular a autonomia do texto, de conferir-lhe o estatuto de "existência semiótica" de modo tão firme como aquele da "realidade dos objetos matemáticos" (GREIMAS, 1974, p. 312). Trata-se do que ele mesmo entende como condição prévia da análise, a da "preparação filológica do texto": "é preciso saber o que é um texto, quer sejamos historiadores, linguistas ou lógicos; o texto é o ponto de partida e estaca de fixação (point d'ancrage) de nossas vociferações, pode-se di-

7 “Vous pouvez regarder de tous les côtés, c'est chaque fois une apparence différente, mais le cube, en tant que tel, reste identique de toute éternité. Voilà une bonne définition du discours en tant qu'objet autonome - " hors du texte pas de salut »! C'est une définition qui nous permet de parler du discours indépendamment des variables que constituent l'émetteur et le récepteur. Il y a toujours le texte, comme le cube; il y a la structure textuelle ou narrative, comme un invariant sur lequel peuvent se fonder nos analyses. Il ne s'agit pas de réduire cet invariant, comme on le fait trop souvent, soit au sujet de l'énonciation soit à l'énonciataire." (in ARRIVE ; COQUET, 1987, p. 311). 
zer que ele os justifica e os funda." (GREIMAS, 1974, p. 302).

Quer portanto parecer que nessas manifestações de Greimas o que está em jogo não é o cunho imanente do texto, mas a pertinência semiótica de conferir-lhe uma existência semiótica autônoma e suficiente para levar adiante a descrição e, a partir do texto, irradiá-la para os polos do enunciador e do enunciatário sem deixar a nau à deriva. Que essa existência semiótica seja imanente, que todos os conceitos acionados para a descrição levem o cunho da imanência, porque construídos do interior do discurso, da língua, isso nada têm a ver com limitação ou reducionismo.

Por isso, quando Fontanille prossegue o desenvolvimento de seu Pratiques sémiotiques; quando amplia o horizonte dos objetos semióticos em direção à abrangência de uma semiótica da cultura ou de uma semiosfera (Lótman) e, para isso, propõe criar diversos "planos de imanência", no meu entendimento, a proposta parece um tanto confusa. Com efeito, toma como ponto de partida um "plano de experiência" - "fenômenos que se oferecem aos diversos modos da apreensão sensível" - cuja conversão em planos de imanência estariam submetidos a uma condição:

Um plano de experiência só pode ser convertido num plano de imanência se e somente se ele permite a constituição de uma semiótica-objeto, dito de outro modo, se ele faz aparecer a possibilidade de uma função semiótica entre um plano da expressão e um plano do conteúdo. (FONTANILLE, 2008a, p. 17-18, tradução nossa) ${ }^{8}$.

Ora, a condição interposta acaba por admitir implicita-

8 "Un plan d'expérience ne peut être converti en un plan d'immanence que si et seulement s'il donne lieu à la constitution d'une sémiotique-objet, autrement dit s'il fait apparaître la possibilité d'une fonction sémiotique entre un plan d'expression et un plan du contenu". 
mente que haja planos de experiência fenomenológica que fujam a isso, qual seja, objetos que não se deixem ver como linguagem (como função semiótica entre conteúdo e expressão). E isso, a meu ver, significa pôr simplesmente em cheque a formulação maior da imanência greimasiana que abrange como linguagem (expressão e conteúdo) não apenas o mundo humano, mas até mesmo a macrossemiótica do mundo natural. Noutros termos, Fontanille cria microuniversos imanentes cada um com seu plano de imanência individual. E isso perturba a gestão ampla da imanência, o "plano de imanência" global que abranja toda heterogeneidade, como vimos há pouco nos argumentos de Bordron, que considero ser a ideia preconizada por Hjelmslev e Greimas e defendida aqui. A ampliação do horizonte de atuação, qual seja a correção do slogan proposta por Fontanille (2008b, p. 19), para "fora dos objetos-semióticos não há salvação", não basta para atender a imanência ampla, epistemológica. Porque objetos que não sejam semióticos simplesmente não há. Se é que haja alguma possível correção e ampliação do adágio de Greimas só teria de ser: fora da linguagem (imanente) não há salvação.

Sem ter a presunção de dar por fechada a questão, o entendimento de imanência ampla, epistemológica e não apenas metodológica, não permite estratificar a imanência. Não há então que se cogitar, como o faz Fontanille (2008b, p. 15), em "fixação dos limites da imanência", mas tão somente acolher uma exfoliação dos níveis de pertinência das análises, assim como Benveniste (1991) o fizera no seu famoso texto "Os níveis de análise linguística", texto que lhe serviu de inspiração. Noutros termos, para meu entendimento, os conceitos de imanência e de pertinência ficaram amalgamados, quase homologados, quando na verdade adentram a teoria por portas distintas. 


\section{Imanência e princípio de realidade em J. C. Coquet}

Como premissa a este item devo confessar enorme dificuldade de entender o alvo preciso dos ataques veementes de J. C. Coquet contra o conceito de imanência e mais amplamente a sua virulência contra a teoria de Hjelmslev. A leitura que faço sobre sua estratégia global de criticar e demarcar-se do estruturalismo conceptual de Hjelmslev (e de Greimas), e de pleitear sua teoria como fenomenologia da linguagem, melhor, de uma "fenomenologia aplicada à linguística e à semiótica" (COQUET, 1997, p. 1), via H. Pos, M. Merleau-Ponty e E. Benveniste, seu triunvirato de patronos, me leva constantemente a concluir que ele força muito as cartas em jogo. $\mathrm{Na}$ ânsia de demarcação - da sua semiótica subjetal contra a semiótica objetal que atribui a Greimas, alcunha jamais acatada por este; da sua fenomenologia da enunciação contra a semiótica do enunciado de Greimas, também jamais acatado nessa restrição - claudica em equívocos às vezes primários, não obstante sua agudíssima erudição e conhecimento teórico, o que me deixa perplexo e indeciso quanto à leitura que procedo. De modo que admito deixar in sursis, e sob suspeição, a argumentação que desenvolvo logo abaixo contra suas ideias, até onde consigo alcançá-las.

No que se refere ao nosso restrito contexto imediato, de confrontar o princípio da imanência com o que ele chama de princípio de realidade, Coquet parece criar um antagonismo entre esses dois princípios que, a meu ver, não se justifica inteiramente. Numa leitura geral, a opção hjelmsleviana de priorizar a forma em detrimento da substância; de priorizar as relações de dependência e pontos de interseção como definidores do objeto, perante a concepção do realismo ingênuo 
que toma primeiro o objeto já dado para em seguida estabelecer relações, isso parece significar a Coquet um abandono do mundo concreto, da realidade da linguagem, em prol de um mundo etéreo, de sua imanência. Tal é o que entendo, por exemplo, quando abro seu mais importante e antigo artigo sobre a questão, intitulado "Réalité et principe d'immanence". 0 artigo recebeu primeira publicação em 1991, tendo sido retomado como capítulo em seu livro La quête du sens. Le langage en question (COQUET, 1997, p. 235-250):

A língua é um objeto abstrato em que só contam as relações entre os termos. Esse princípio de imanência, tal como ao menos o tem compreendido os linguistas, não mereceria quase comentários, de tanto que é conhecido, aceito e continuamente aplicado há mais de meio século [...]. Pensamento sistêmico que não leva em conta a "realidade". Pensamento comum, em essência, a Saussure e a Hjelmslev. A escolha é clara: de um lado o "pensamento científico", do outro um "realismo ingênuo". (COQUET, 1997, p. 235, tradução nossa) ${ }^{9}$.

Notemos primeiramente desde aqui que a imanência não é entendida, como em Fontanille, como limitação da análise apenas ao texto, mas como "exclusão do princípio de realidade" da linguagem (COQUET, 2007, p. 81, grifo nosso) em prol de uma reconstrução conceptual, por assim dizer, num limbo formal. Só contaria o formalismo de suas categorias, abandonada a própria materialidade substancial da língua. Para Coquet, pelo princípio de imanência de Hjelmslev, os fe-

9 "La langue est un objet abstrait où seules comptent les relations entre les termes. Ce principe d'immanence, tel du moins que l'ont compris les linguistes, ne mériterait guère de commentaires tant il est connu, accepté et continûment appliqué depuis plus d'un demi-siècle [...] Pensée systémique qui n'a que faire de la "réalité ». Pensée commune pour l'essentiel à Saussure et à Hjelmslev. Le choix est clair : d'un côté la " pensée scientifique », de l'autre " un réalisme naïf " ". 
nômenos, acontecimentos, percepções, movimento, ficam "reduzidos a termos abstratos, entram num sistema fechado de relações". Trata-se de um "paradigma formalista" em que "a sintagmática é o plano em que se encadeiam puras relações e a língua, uma forma e nada mais" (COQUET, 1997, p. 2-4). Isso é visto por ele como extremo reducionismo metodológico e epistemológico, a ponto de não conter a ironia cáustica:

Para o imanentista, há uma fronteira intransponível entre o universo sensível e o universo inteligível e, dado que apesar dos pesares não é possível negar a existência do primeiro, sua posição é de reduzir ao tamanho do leito de Procusto o talhe do segundo. (COQUET, 2007, p. 45, tradução nossa) ${ }^{10}$.

Ora, confundir a imanência metodológica de Hjelmslev - a construção conceptual da linguística de seu interior, sem apelo à conceptualidades externas de disciplinas de outras plagas - com abstração, formalismo e reducionismo; confundir imanência e metodologia estrutural - que entende a relação como prioritária aos termos-objeto - enfim, confundir imanência com a exclusão da realidade numa estrutura que toma a forma como pertinente mas que jamais abandona a substância formada, tudo isso é a meu ver hipertrofiar a teoria hjelmsleviana. Cria-lhe uma caricatura anamorfizada e, em seguida, critica mordazmente a nova criatura medonha. Quando me deparo com confusões e forçamentos desse naipe, só tendo a concordar com S. Badir sobre as "contra-verdades" nas "veleidades de demarcação teórica" de Coquet a respeito

10 "Pour l'immanentiste, il y a une frontière infranchissable entre l'univers sensible et l'univers intelligible et puisqu'il n'est pas possible malgré tout de nier l'existence du premier, sa position est de le réduire aux mesures du lit de Procuste que le second s'est taillé. ". 
de Hjelmslev (BADIR, 2014, p. 30) ${ }^{11}$.

A condenação do formalismo de Hjelmslev por Coquet chega a ser a tal ponto obsedante que o leva a ter necessidade de remontar aos anos 1930 e servir-se de uma carta das correspondências de Troubetzkoy, em que este se defende ele próprio da acusação de abstração que o movimento fonológico vinha recebendo então:

Não há nenhum perigo desde que não se esqueça que o fim de todo edifício e que não se perca o contato com o material concreto. Tudo só se torna realmente perigoso quando o prazer de forjar conceitos se torna seu fim em si mesmo, como é o caso dos glossemáticos dinamarqueses. Mas os fonólogos [...] estão a cem léguas de semelhante perigo [...]. Basta comparar meus escritos com aqueles de Louis Hjelmslev para sentir a diferença. (apud COQUET, 1997, p. 4, tradução nossa $)^{12}$.

É difícil evitar e o mínimo a dizer é que tais argumentos navegam entre o mar do ridículo e o oceano do descabimento. A autojustificativa do príncipe é cômica tanto quanto frágil, incabível no debate científico, indigna da sua estatura teórica. Nenhum álibi consegue redimi-la, nem mesmo o gênero correspondência. 0 descabimento, à sua vez, fica por conta de Coquet valer-se dela, e por duas vezes, em seu livro (cf. também Coquet, 1997, p. 236). 0 episódio, carta e uso da carta, é

11 Nem mesmo lhe cabe de álibi, pelo contrário, o fato de ele apenas se utilizar, nesses dois livros que servem aqui de base $(1997,2007)$, da pior tradução do Prolégomènes para o francês, uma primeira de 1968 que logo foi abandonada e substituída pela tradução de Una Canger em 1971, fato sobejamente conhecido no campo.

12 "Il n'y a aucun danger tant qu'on n'oublie pas le but de tout l'édifice et qu'on ne perd pas le contact avec le matériel concret. Tout ne devient vraiment dangereux que quand le plaisir de forger des concepts devient à soi-même sa propre fin, comme c'est le cas chez les glossématiciens danois. Mais les phonologues [...] sont à cent lieues d'un pareil danger. Il [...] suffit de comparer mes écrits avec ceux de Louis Hjelmslev pour sentir la différence.". 
bem o tipo mordaz de crítica que afinal, na verdade, apenas denuncia a fragilidade cabal dos argumentos, em ambos.

Para reforçar a exigência do princípio de realidade, Coquet recorre fartas vezes a seu filósofo preferido, Merleau-Ponty. Já na abertura de sua Quête du sens, numa introdução que recebe título portentoso, "O poder da fenomenologia", cita a bela e pertinente metáfora do filósofo: a linguagem é "nosso elemento como a água é o elemento dos peixes". Quer com isso enfatizar que ela não pode ser olhada "de fora" como objeto que se possa contentar de "observar e de descrever": ela é "constitutiva de nossa realidade" (COQUET, 1997, p. 1).

Ora, sem melindrar a bela metáfora do filósofo - embora para meu entendimento perca em vigor poético perante a metáfora da tecelagem, na primeira página dos Prolégomènes de Hjelmslev, qual seja, a linguagem como "fio profundamente tecido na trama do pensamento" (1971a, p. 9) - ocorre que o linguista fenomenólogo confunde aqui duas instâncias que jamais podem sê-lo em nenhuma atividade teórica: a vivência da linguagem, pelo falante, e a sua observação e descrição, pelo teórico. As duas metáforas, a do filósofo tanto quanto a do linguista, confirmam bem a vivência pelo falante, mas a descrição do teórico em nada vem para contestar a realidade de sua vivência na linguagem.

0 mesmo equívoco parece ocorrer ao longo de todo o seu livro Phusis et Logos. Une phénoménologie du langage (COQUET, 2007). Segundo a leitura que pude alcançar, haveria dois níveis de realidade: da phusis e do logos. 0 primeiro responde pelo mundo sensível, pelo primeiro contato direto com o mundo, contato levado a efeito pelo corpo (phusis); o segundo é aquele transcrito pelas instâncias enunciantes do discurso (logos): "há um primeiro nível de realidade (o mundo sensível) que é 'traduzido' para um segundo nível de reali- 
dade, o discurso e sua instância. Aí está o ponto fundamental de uma fenomenologia da linguagem." (COQUET, 2007, p. 58). Para a fenomenologia da linguagem de Coquet, o logos é a resultante (point d'aboutissement) da phusis, é a tradução desta naquele; o corpo, tomado sempre no sentido merleau-pontiano, procede da phusis e em seguida comunica ao espírito ou ao pensamento a informação que pôde recolher. De modo que o primeiro tempo, de contato do corpo com o mundo, é o tempo da "apreensão" (prise) e o segundo, o de sua resolução em "depreensão/compreensão" (reprise) (COQUET, 2007, p. 5-8):

No momento da apreensão (prise), é a instância corporal que edifica seu universo; procedendo por tateamentos sucessivos, ela reconstrói um território familiar. No momento da depreensão/compreensão (reprise) [...] a instância judicativa organiza (met en forme) a experiência que lhe serve de referência e de propósito. (COQUET, 2007, p. 9, tradução nossa $)^{13}$.

A dualidade proposta tem ao ver de Coquet o mérito de separar a "singularidade do ato perceptivo" perante e em oposição ao "ato cognitivo" de modo que ficar apenas com o logos seria desconsiderar o papel "fundador" da phusis, isto é, da natureza, daquilo que mais importa: o "primeiro solo" da nossa experiência (COQUET, 2007, p. 6). De modo que nessa dualidade a linguagem "é bem uma realidade de segunda ordem” (COQUET, 2007, p. 75):

A uma realidade de primeira ordem, aquela do acontecimento e da experiência que temos do acontecimento, na medida

13 "Au moment de la prise, c'est l'instance corporelle qui édifie son univers ; procédant par tâtonnements successifs, elle reconstruit un territoire familier. Au moment de la reprise [...] l'instance judicative met en forme l'expérience qui lui sert de référence et de propos.". 
em que o apreendemos [...] ou em que nos arrebata (qu'il a prise sur nous] [...] sucede uma realidade de segunda ordem, aquela que nós elaboramos a partir da realidade da primeira ordem. (COQUET, 2007, p. 105, tradução nossa) ${ }^{14}$.

Não é difícil notar, perante todo o encaminhamento dessas citações, que sobressai o realismo do corpo como um primeiro solo da experiência sensível, anterior ao exercício da linguagem. Ligados a esse corpo que percebe estão, segundo ele, os "efeitos da paixão", a "inibição devida ao medo" tanto quanto o "desejo", referidas as expressões ao universo freudiano da psicanálise (COQUET, 2007, p. 10). Coquet convoca também às suas fileiras algumas reflexões de P. Valéry, para considerar que a percepção da luz, das cores, não é a visão; a percepção das cores, da luz "cabe à phusis, e a representação que nós lhe damos cabe ao logos". Ora, um pouco adiante, não mais que cinco linhas abaixo enuncia isto: "cada um percebe segundo suas palavras antes do que a partir de sua retina" (COQUET, 2007, p. 6). A perda do controle conceptual aqui é flagrante; a última frase diz exatamente o contrário da primeira: se cada um percebe segundo suas palavras, é pelo logos que o faz, não pela phusis.

Esse último caso me permite questionar o empreendimento de Coquet como um todo. Como é possível conceber alguma competência perceptual, do corpo, que não lhe advenha de alguma linguagem? Perceber a cor, sentir o medo, ter o desejo, se retiramos disso algum critério categorial mínimo, semiolinguageiro, nada é medo, cor ou desejo desde o "fundo" do corpo. Tudo não passa de estrebuchamentos de nervos,

14 “À une réalité de premier ordre, celle de l'événement et de l'expérience que nous avons de l'événement, dans la mesure où nous avons prise sur lui [...] ou qu'il a prise sur nous [...] succède une réalité de second ordre, celle que nous élaborons à partir de la réalité du premier ordre.". 
de trânsitos celulares, de neurotransmissões em quantidades sinápticas. Nem isso, a bem dizer: na verdade trocamos o logos da linguagem natural pelos logoi do discurso científico da neurobiologia, nada mais. Não há corpo fora de (alguma) linguagem ou anterior a ela. 0 que poderá ser uma "instância corporal" a "edificar seu universo" por "tateamentos sucessivos" e reconstruir seu "território familiar" (cf. citação penúltima em destaque) sem algum protocritério que lhe advenha de alguma semiologia? No meu entendimento, tais frases dificilmente evitam a impressão de estar desavisadamente perdidas sob a ilusão e charme de atingir o âmago do 'fenomenológico' do corpo, da percepção, da carne e tutti quanti. Enfim, para meu entendimento, a phusis de Coquet é um logos que não se deu conta.

Não apenas isso: toda a conceptualidade que Coquet empreende para distinguir níveis de realidade, para conceptualizar, em phusis e logos, os dois níveis a serem operados por sua tipologia de sujeitos - sujeito, quase-sujeito e não sujeito -, tudo isso o faz inelutavelmente sair do fenômeno, para notá-lo, observá-lo, tipificá-lo de fora, como se vê, tarefa nada mais nada menos do que a mesma categorização formal de que acusa equivocadamente a Hjelmslev. Não se está no corpo falando muito dele, só falando dele, estando sob seu charme; não se está na percepção atribuindo-lhe o estatuto de primeiro solo da experiência. Não se tem como evitar a distância epistemológica entre o fenômeno e sua descrição. São dados primários não apenas de qualquer procedimento científico de teorização e descrição, mas também de qualquer observação do fenomenólogo sobre a "coisa mesma". Causamme a perplexidade, acima anunciada em premissa, não vê-los assumidos por um pesquisador de tão alta competência.

Por fim, se toda linguagem é imanente então os dois níveis 
de realidade que pleiteia Coquet não estão excluídos da imanência ampla, epistemológica, que aqui vem sendo defendida. Não há, pois, oposição legitimável entre imanência e realidade. Esta só tem sentido fenomenológico se subordinado àquela.

\section{A imanência em questão: Alessandro Zinna}

Este item tem por fim prestar reconhecimento aos incessantes esforços desse pesquisador, a partir de um colóquio da Associação Francesa de Semiótica em Paris em 2007 e em seguida em 2010 em Lyon, em reunir e publicar debates atuais sobre o que ele mesmo chama de "conflitivas relações entre a semiótica e a imanência":

A situação era a mesma [nos dois congressos]: ou os semioticistas repeliam um conceito que consideravam um lastro coercitivo do passado, ou então faziam suas investigações sem questionarem se esse e outros fundamentos da teoria que praticavam sustentavam epistemologicamente seus trabalhos. Porém, tanto num caso como no outro reinava a confusão, o mal-entendido, o equívoco, a falta de um retorno às fontes para repensar do que se fala quando se alude à imanência. (ZINNA, MORENO, 2014, p. 5-6, tradução nossa) ${ }^{15}$.

Tal abertura anuncia o número 31 da revista Tópicos del Seminario (2014), com temática geral intitulada "La inmanencia en cuestión", o primeiro já publicado de uma trilogia cujos

15 "La situación era la misma [nos dois congressos]: o bien los semiotistas rechazaban un concepto que consideraban un lastre coercitivo del pasado, o bien hacían sus investigaciones sin cuestionarse si éste y otros fundamentos de la teoría que practicaban sostenían epistemológicamente sus trabajos. Pero tanto en un caso como en el otro reinaba la confusión, el malentendido, el equívoco, la falta de un retorno a las fuentes para repensar de qué se habla cuando se alude a la inmanencia.". 
números seguintes Zinna, juntamente com Luisa R. Moreno, estão prestes a editar. A temática e os debates sobre a questão da imanência se tornaram um tópico "altamente sensível para a teoria da linguagem" a ponto de terem sido retomados no Seminário de Paris do ano letivo 2013-2014. Sem haver espaço aqui para examinar em detalhes as posições enunciadas nesse número de revista, chamo a atenção apenas para a leitura que apresenta o próprio Zilberberg (2014, p. 195-208), para que seja possível expor sua semiótica tensiva perante a imanência.

Zilberberg examina o conceito de imanência não na perspectiva de diretiva metodológica da teoria, mas como um modo de significância que partilha com o modo da transcendência o imaginário humano, a partir da filosofia de Cassirer. Examina o par imanência vs. transcendência na análise de seu potencial de valor perante os conteúdos humanos. Assim a imanência responde pelos valores de concentração, de absoluto, enquanto que a transcendência rege os valores de expansão, de universo. A primeira restringe, seleciona, visa à unicidade, enquanto a segunda mistura, abrange e visa à universalidade. Isso lhe permite dizer que, enquanto sistema de puros valores, a língua para Saussure é uma defesa da tese da imanência, assim como o conceito de "esquema" de Hjelmslev, perante o de "norma" e "uso" que, à sua vez, estipulam a transcendência.

Vê-se claramente que a operação analítica que procede Zilberberg em sua semiótica tensiva não faz uso explícito de teorização epistemológica tal como vimos aqui fazendo da imanência. E é justamente este o ponto a destacar. São raras as suas manifestações diretas e explícitas sobre o alcance epistemológico da imanência. Nem por isso sua teoria não se deixa ver em linhagem direta com as diretrizes fundamentais de 
Hjelmslev. Ao contrário, é a meu ver a única teoria semiótica que continua a preservar a estrita imanência de método hjelmsleviana e, no caso aqui em discussão, a que melhor pode testemunhar como se pode efetuar o exercício teórico-analítico sob a regência de uma epistemologia discursiva imanente.

\section{A semiótica tensiva: o afeto vencido mot à mot}

A chamada semiótica tensiva, nos apresenta com modéstia C. Zilberberg (2006, p. 9), "se contenta em mostrar um ponto de vista que centraliza grandezas até então julgadas menores: as grandezas afetivas". Sem dúvida temos de saudar poder ver a semiótica pôr o dedo, por assim dizer, no barro adâmico da subjetividade, região tão delicada da vivência humana. Se os esforços de Zilberberg, na busca de uma "gramática" do afeto um dia obtiverem sucesso terá sido a realização do sonho de Hjelmslev: os confins da substância mesma da vivência, o mundo dos afetos enfim demonstrado pelas formas imanentes da linguagem, por sua gramática interna, tensiva: o afeto vencido mot à mot, para reverberar aqui expressão famosa de Mallarmé (le hasard vaincu mot à mot).

Desde sua primeira manifestação teórica de maior extensão - o livro Essais sur les modalités tensives (1981) - Zilberberg impressiona mentes agudas como a de um filósofo, Herman Parret, por sua "genialidade" (elogio ouvido num curso dado em 1985 na USP), conquanto repreenda-lhe desde então a proliferação metalinguística. Repete o elogio e a repreensão quando prefacia sua seguinte obra de fôlego, de 1988, intitulada Raison et poétique du sens, que recebeu tradução brasileira (2006). 
"Semiótica sonhadora, sonhada e intermitente", "semiótica do tremor, da cintilação, da hesitação", "semiótica lúdica, um pouco fantasiosa" [...]. A reflexão semiótica de Zilberberg, no panorama das semióticas forjadas em torno e a partir da obra de A. J. Greimas, é provavelmente a mais original, a mais formal, a mais radical, a mais poética, a mais "genial" (se admitirmos com Kant que o gênio se constitui de um entrelaçamento ideal do entendimento e da imaginação). (ZILBERBERG, 2006, p. 11).

Os elogios lhe são cabíveis porque encontra no texto prefaciado "fontes de entusiasmo". Mas também o vê com "perplexidades e preocupações" e até mesmo sente decair em "um certo delírio terminológico" (ZILBERBERG, 2006, p. 1213). Certamente Parret repetiria os elogios e as reprimendas caso porventura tivesse de se manifestar sobre outras duas obras posteriores de Zilberberg que nos servirão mais diretamente aqui: Elementos de Semiótica Tensiva (2011) e La structure tensive (2012).

Filho direto de Hjelmslev - ou semiótica "filial" como se expressa em sua homenagem H. Parret (2009, p. 237) - conquanto indócil quando entende dever retrucar, é natural que herdasse de Copenhague o agudo senso da criação e proliferação terminológica. Curioso dado a ressaltar, outro grande linguista, E. Benveniste, não o recriminaria. Num capítulo importante de seus Problemas de Linguística Geral, em que busca a "gênese do termo scientifique", o notável linguista assim se expressa:

A constituição de uma terminologia própria marca, em toda ciência, o advento e o desenvolvimento de uma conceitualização nova, assinalando, assim, um momento decisivo de sua história. Poder-se-ia mesmo dizer que a história particular de uma ciência se resume na de seus termos específicos. Uma ciência só começa a existir ou consegue se impor na medida em que faz existir e em que impõe seus conceitos 
através de sua denominação. Ela não tem outro meio de estabelecer sua legitimidade senão por especificar seu objeto denominando-o, podendo este constituir uma ordem de fenômenos, um domínio novo ou um modo novo de relação entre certos dados. (BENVENISTE, 1989, p. 252, grifo nosso).

Esse momento terminológico é de tal importe que Benveniste considera-o decisivo no nascimento de uma ciência e também constante no seu andamento. Denominar, isto é, criar um conceito é de tal forma necessário que se torna "a operação ao mesmo tempo primeira e última de uma ciência" (BENVENISTE, 1989, p. 247). Não se trata portanto de delírio tal como pôde parecer a Parret (e parece a vários semioticistas), muito menos do gozo forjar conceitos como fim último da teoria, como o entendeu o desastrado comentário de Troubetzkoy, visto acima. Ao contrário, é uma exigência inelutável do avanço de qualquer ciência. Quem fica pelo meio do caminho começa a cair na contemplação repetida dos conceitos já lançados, a um passo de capelas e dogmatismos, cede primeiro nos termos, depois nas ideias.

Do ponto de vista da presente reflexão, nada mais consequente do que a proliferação conceptual. Isto é, do ponto de vista do "maximalismo hjelmsleviano" - expressão feliz de Zilberberg (2006, p. 94) - segundo o qual a linguagem é a forma de conhecimento do mundo, nada mais consequente do que explorar exaustivamente em teoria da linguagem as categorias que mobilizam o funcionamento integral da linguagem para a produção da significância e conhecimento do mundo. Se o Résumé de Hjelmslev (1975), com perto de 500 definições e mais de 200 regras, não vingou mundo afora, por contingências de publicação, de vida, de tempo e das forças de divulgação superiores da teoria de Jakobson \& Troubetzkoy, isso não impede de notar que, somadas todas as categorias, terminologias e metalinguagens das fonologias, das fonéticas, 
das morfologias e das sintaxes que daí se originaram e evoluíram, tais terminologias ultrapassem em muito as centenas propostas por Hjelmslev.

Então a mordacidade anterior dos comentários de Troubetzkoy continuam despropositados assim como a recente queixa de Parret não tem fundamento. Zilberberg busca categorizar progressivamente um terreno resistente à semiótica anterior - semiótica do inteligível, do categorial. Busca morder o vasto mundo do afeto, o qual, inspirado na filosofia de Cassirer, se lhe apresenta como "chave cognitiva" - de sua semiótica do sensível, ou das suas Analíticas do sensível, belo e ajustado título de uma obra em sua homenagem, organizada por D. Ablali e S. Badir (2009) ${ }^{16}$. À teoria da linguagem de Hjelmslev e à semiótica categorial de Greimas, Zilberberg vem acrescentar um leque terminológico e operacional para uma espécie de desagravo ao afeto, às grandezas que ele inaugura, às dependências que ele exige, com vistas à sua integração na teoria semiótica geral. Bem entendido, não se trata da substituição de um por outro, do inteligível pelo sensível, mas antes da "coalescência do sensível e do inteligível", é a isso que Zilberberg chama tensividade (2012a, p. 21).

\section{A semiótica tensiva: entre a gramática imanente e a fenomenologia transcendente}

A semiótica tensiva não é fácil de ser examinada. Fontanille tem mesmo razão, em sua participação às homenagens ao

16 A expressão "chave cognitiva" por Zilberberg (1994, p. 51-87) não conota qualquer prevalência da dimensão cognitiva, regência do inteligível, como se fora derradeira trincheira de resistência à perda de seus privilégios anteriores. Vejo nele simplesmente o pleito de depositar no afeto a própria chave da "inteligibilidade" mais funda, afetiva, do mundo da significação. 
semioticista, intitulada "Claude Zilberberg: um pensamento a ser seguido", ao testemunhar "um exercício difícil e excitante: seguir e penetrar seu pensamento" (in ABLALI; BADIR, 2009, p. 225). Por insegurança, dado o recente das proposituras tensivas, por economia e pertinência, dados os objetivos centrais deste artigo, não entro aqui em comentário de minúcias. Interessa antes os grandes gestos de sua entrada no campo geral dos estudos semióticos frente à hipótese aqui lançada de uma epistemologia discursiva deduzida da linguagem. Quanto a isso, tenho a destacar dois grandes gestos que representam sua teoria para a hipótese aqui em questão.

0 primeiro desses grandes gestos deve ser aferido pela sua firme posição e consequente manutenção das bases linguísticas (saussuriana e hjelmsleviana) para seus intentos frente aos acenos e acentos fenomenológicos que há bom tempo vêm atualmente imperando no campo semiótico. Para anotá-lo, um pequeno recuo no tempo é suficiente.

Com pouca repercussão nos primeiros vinte anos de leitura de seu Sémantique structurale (1966), período em que a semiótica se deteve (por coerência de método) nos limites do texto, uma frase de Greimas propunha, nas páginas inaugurais desse livro, que a melhor estratégia de entrada para a investigação do sentido e da significação era a de assumir "a percepção como lugar não linguístico onde se situa a apreensão da significação" (GREIMAS, 1966, p. 8-9, grifo nosso). Admitia, logo em seguida suas preferências subjetivas pela teoria da percepção da filosofia fenomenológica de M. Merleau-Ponty. Eram primeiros posicionamentos - "com conhecimento de causa" dizia Greimas à ocasião - da sua então semântica estrutural perante a fenomenologia, alguns anos depois de ter saudado as pesquisas do filósofo, juntamente com a do antropólogo Lévi-Strauss, pelos esforços que faziam 
em atualizar Saussure para o ambiente de meados do seu século (GREIMAS, 1956). Viu-se nisso um primeiro aceno em direção à fenomenologia criada em Husserl e retrabalhada por Merleau-Ponty.

0 aporte fenomenológico na teorização e conceptualizações semióticas se deixou notar mais diretamente a partir do Sémiotique des passions (1991), de Greimas com Fontanille, quando da efetiva entrada do corpo na semiose, tendo por carro chefe a primazia da percepção e revitalizados nisso os correlatos dela, a interocepção, a exterocepção e a propriocepção, todos reconvocados do Sémantique structurale para dar conta do que se exigia como as pré-condições sensíveis do advento da significação. A frase do Sémantique structurale ficou famosa. Tida por novo adágio e tidas por aval as reflexões fortemente epistemológicas de uma centena de páginas de abertura do Sémiotique des passions, eis que desde finais dos anos 90 do século findo, muitos semioticistas se veem engajados numa aproximação forte com a filosofia fenomenológica.

O pleito de um "primado da percepção" (MERLEAU-PONTY, 1996) fez com que a percepção, para vários semioticistas, se tornasse pouco a pouco o locus privilegiado de investigação sobre o sentido, lugar ante-predicativo, segundo o filósofo, portanto lugar aquém da linguagem ${ }^{17}$. Percepção, corpo-próprio, carne, campo de presença, conceitos filosóficos da fenomenologia, tornaram-se e são hoje manejados em usos fartos e correntes no campo semiótico. É como se os limites do texto tivessem se provado por demais limitados e insuficientes para dar conta da complexidade do sentido. A bússola da percepção aprumada e o leme do corpo-próprio ajustado à semiose, deu-se a partida 
para aventura em busca dos mares de origem onde se aportaria na emergência primeira do sentido, espécie de périplo fenomenológico da nau semiótica.

Desde então, o primado da percepção vem se impondo pouco a pouco, a tal ponto que é possível atualmente notar uma espécie de império, quase imperativo, da percepção encarnada, diretamente soldada ao mundo da experiência sensível, como primeira camada de significação, a montante, encarregada de reger todas as outras, a jusante. Doravante, a semiótica terá de ser experiencial e carnal, ou não será. Tal parece a palavra de ordem desse périplo fenomenológico. Sobre o sentido, nada de sensato se poderá mais dizer a não ser pelos sentidos criados na camada profunda da percepção. A carne, por assim dizer, se impôs e depôs o in principio erat verbum. As razões semióticas (do texto, e de sua forma semiótica imanente) cedem então o passo aos argumentos fenomenológicos (da percepção e da sua substância corporal transcendente). Em suma, tudo significou uma espécie de impulsão da semiótica para sair do sujeito de papel, do texto e de seu programa narrativo, em direção ao espaço da vida, à vivência dos falantes, à experiência cotidiana, intersubjetiva, em direção às práticas significantes humanas, enfim uma semiótica experiencial em ato. 0 recurso imediato foi, pois, navegar em águas fenomenológicas. De fato, o fato semiótico não era mais o sujeito de papel encalacrado num programa narrativo que, numa crítica um tanto mordaz de Coquet - cito de memória - não fazia mais do que seu "dever de casa" no curso actancial e modal de seus programas de base e de uso. O sujeito agora devia ser interceptado no seu corpo, na sua carne, em presença, na lide da experiência, em ato.

Zilberberg (2011, p. 41), também atento ao novo contexto, assim situa sua semiótica tensiva: "Esta se preocupa, antes 
de tudo, com a relação existencial, imediata, imperativa, entre o eu e o não-eu, concebida por Merleau-Ponty na Fenomenologia da Percepção como 'uma primeira camada de significação'”.

Outras e fartas serão as remissões que fará ao filósofo ao longo de suas proposições tensivas; outras e fartas serão as vezes em que ele estará atento e sensível ao sensível. Mas, e seja isso sublinhado, há algo de singular que difere em muito sua navegação daquela do périplo fenomenológico dos demais semioticistas. É a precaução e prevenção de Zilberberg quanto à coerência da teoria semiótica integral:

Efetiva ou não, justificada ou não, essa "virada fenomenológica" constitui uma intimação. Fazendo suas as posições da fenomenologia, em especial a que se configura na obra de Merleau-Ponty, não estaria a semiótica se afastando de sua dupla referência, saussuriana e hjelmsleviana? [...] Deixemos de lado, por enquanto, a questão de saber se uma disciplina exigente pode trocar de bases conceituais sem que isso acarrete importantes consequências. (ZILBERBERG, 2011, p. 12).

É uma bela advertência, mesmo que sobre a questão levantada ele próprio não empreenda em todo o conjunto do seu livro uma discussão mais "dura", a qual, a bem dizer, urge ser colocada e enfrentada pelo campo semiótico. Mesmo assim a advertência já o permite situar-se:

O que acaba de ser dito permite-nos formular nosso projeto pessoal. Na mesma medida em que a prevalência concedida ao percebido parece afastar a semiótica de suas referências linguísticas declaradas, a atenção que dedicamos com e a partir de outros autores, ao vivenciado e ao experienciado permite manter intacta, sem que se possa falar em paradoxo ou provocação, a referência linguística. (ZILBERBERG, 2011, p. 12, grifo nosso). 
É assim que ele proporá uma gramática tensiva do afeto, dentro e não fora da base linguística saussuriana e hjelmsleviana, a demonstrar que a expressão não é antinômica nos termos. Sua teorização tensiva global manterá a marca geral da imanência hjelmsleviana, a marca geral do formalismo linguageiro de Copenhague:

Nós tentamos mostrar que uma teoria reputada como "fria" estava em condições de trazer uma contribuição decisiva à descrição de conteúdos sentidos como "quentes", o que foi possível porque as categorias conservadas por Hjelmslev são grosso modo igualmente pertinentes para a conceptualização e a formalização do afeto; a potência, para alguns, o caráter todo poderoso, do afeto se deve não ao relaxamento da forma mas, ao contrário, à sua difamação. (ZILBERBERG, 2001, p. 100) ${ }^{18}$.

Trata-se a meu ver da estrita observância às últimas páginas do Prolegômenos de Hjelmslev quando este retoma o direito de entrada na teoria dos dados até então tidos por transcendentes, a fenomenologia da vida humana, o que, em suas palavras, constitui uma "fisionomia particular":

O simples ato de fala obriga o pesquisador a introduzir por catálise um sistema que seja coesivo com esse ato; a fisionomia particular é uma totalidade que cabe ao linguista reconhecer através da análise e da síntese [...]. Catálise sobre catálise obrigam a alargar o campo visual até o ponto em que se chegue a levar em conta todas as coesões. (HJELMSLEV, 2003, p. 131).

18 "Nous avons tenté de montrer qu'une théorie réputée "froide » était en mesure d'apporter une contribution décisive à la description de contenus sentis comme "chauds », ce qui a été possible parce que les catégories retenues par Hjelmslev sont grosso modo également celles qui sont pertinentes pour la conceptualisation et la formalisation de l'affect ; la puissance, pour certains la toute-puissance, de l'affect tient non au relâchement de la forme, mais au contraire à son accusation.". 
Mesmo que o linguista se refira aqui ao ato de fala e não a algum outro tipo de experiência vivencial, corporal, não verbal, nada disso importa, importam as coesões a serem perseguidas cataliticamente em sua totalidade. E, a meu ver, o que faz Zilberberg na sua teorização tensiva nada mais é do que identificar novas coesões, criando-lhes primeiramente um "espaço tensivo", articulado em intensidade vs. extensidade, para que tais novas coesões possam "se comunicar", como dependências internas, em interdefinições (cf. ZILBERBERG, 2012, p. 20-36). Assim, os foremas - direção, posição e elã cruzarão suas induções semânticas com aquelas dos aspectos - minimização, atenuação, restabelecimento e recrudescimento - para formarem um tabuleiro de células tensivas que interceptam os signos resultantes não como os semas da semiótica anterior mas como valências e valores em tensão, em vetores de projeção de aumentos e diminuições do tônus de significância dos termos envolvidos.

Para o ilustrar em poucos exemplos, no campo do aspecto: (i) a atenuação induzirá ao "cada vez menos mais"; (ii) a minimização ao "cada vez mais menos"; (iii) o restabelecimento ao "cada vez menos menos"; (iv) o recrudescimento ao "cada vez mais mais". Gera-se assim um tabuleiro em que, nos seus cruzamentos, se evidencia a força heurística dos semantismos dos termos resultantes: por exemplo, a "moderação" se evidenciará como a "retirada de pelo menos um mais"; a "ampliação" se mostrará como "o acréscimo de pelo menos um mais"; a "saturação" como "o acréscimo de mais de um mais" e assim por diante.

Não há razão aqui de avançar para além desses poucos exemplos, e de adentrar fundo nos tabuleiros e verdadeiros mapas tensivos que apresentam uma nova cartografia refinada dos semantismos da linguagem - "catedral de interdefini- 
ções e de interfaces" como se expressa Parret (2009, p. 238). 0 que importa é que as células tensivas de Zilberberg (mais mais, menos menos, mais de menos, menos de mais, cada vez mais, cada vez menos) conseguem a façanha de fornecer a quantificação própria da linguagem, fenomenológica, espécie de, como ele mesmo descobre, "aritmética tensiva, sem dúvida grosseira, porém em conformidade com a língua” (ZILBERBERG, 2011, p. 60). É como se a "álgebra da língua" proposta por Saussure e perseguida por Hjelmslev encontrasse aqui sua expressão mais adequada: uma álgebra tensiva da língua.

Sua proposta de exfoliação dos semantismos dos discursos nos vetores foremáticos, em complemento às oposições sêmicas e classêmicas da semiótica anterior, as correlações conversas e inversas dos esquemas de intensidade e extensidade conseguem uma descoberta ímpar. A proposta das pequenas células tensivas de medida - mais-mais, menos-menos, mais-menos, menos-mais - desempenham para o universo do contínuo dos semantismos o mesmo papel de fundação (desta feita tensiva) que desempenharam para a semiótica anterior as células paradigmáticas e sintagmáticas (então categoriais), cuja melhor síntese veio da pena de Hjelmslev: "ou...ou" - "e...e", as quais regem a paradigmática e a sintagmática geral das linguagens.

No meu entendimento tais células tensivas fazem adentrar a quantidade no mundo da medida do homem como quantificação fenomenológica perante aquilo que as ciências veem como as quantidades cifradas do mundo físico. Amamos nossos entes mais ou menos, cada vez mais ou cada vez menos, e não $45 \%$ ou $95 \%$. Estamos mais próximos ou menos próximos de nossos entes queridos e não a um metro e meio ou dois metros de distância. 
São essas células tensivas que podem ser acionadas em análise imanente, com heurística superior, frente ao modo como as reivindicações fenomenológicas de outros semioticistas tentam acionar fora da imanência da linguagem, no solo primeiro de uma percepção antelinguageira. É como se a semiótica atual estivesse diante da tarefa de enfrentar o que poderíamos convir como uma revanche do contínuo sobre o descontínuo, a revanche do sensível sobre o inteligível, do corpo sobre o espírito, do afeto sobre a cognição, enfim a revanche da vida-em-ato sobre o texto-em-papel, dando uma espécie de rumo sem volta perante as décadas anteriores da linguística de linhagem saussuriana e da semiótica de linhagem hjelmsleviana e greimasiana.

Findo o primeiro, passemos ao segundo grande gesto da teoria tensiva de Zilberberg, para os propósitos da presente reflexão sobre uma epistemologia discursiva de cunho imanente. Ele está no modo como Zilberberg constrói sua metalinguagem conceptual. Sob o imperativo imanente das "dependências internas", sua navegação conceptual tem isso de singular: não faz importações diretas de conceitos da lógica, da filosofia, da matemática, da psicologia, da psicanálise dentre outras tantas teorias. Sua estratégia é de tomar sobretudo de poetas (Mallarmé, Baudelaire), de pensadores livres (Valéry), de filósofos (Cassirer, Deleuze, Merleau-Ponty, Bachelard), de psiquiatras (Binswanger), não importa a proveniência de seus campos, não para importar diretamente conceitos, mas para colher frases, expressões, torneios discursivos, cuja vivacidade semântica e força sugestiva, cuja densidade e tonicidade retóricas lhe sirvam de alicerce para a constituição de sua própria terminologia, isto é, para transformá-las em conceitos dentro do espaço tensivo criado.

Noutros termos, busca sua conceptualização no fundo 
do discurso, nas "racionalidades" discursivas construídas através do pensamento desses autores buscados, seja na longitudinal da diacronia dos discursos humanos, em pensadores de outrora, seja na latitude sincrônica que vige hoje, em pensadores de agora. Quando chegamos em teoria a pleitear que a subjetividade humana é imanente à linguagem, o poeta poderá estar dizendo o mesmo, em poesia: “a gente é cria de palavras" (Manoel de Barros); quando Zilberberg teoriza uma "gramática" do afeto, imanente à linguagem, o escritor poderá estar dizendo o mesmo ao escrever: "infelicidade é questão de prefixo" (Guimarães Rosa). Epistemologia discursiva é in limine apenas reconhecer isto: dar ao discurso, como linguagem em ação, o direito de ser tido por uma verdadeira epistemologia do conhecimento.

\section{Agradecimentos}

Ao CNPq pela bolsa de produtividade que impulsiona, desde o ano 2000, a pesquisa acadêmico-científica que venho trazendo a público.

\section{REFERÊNCIAS}

ABLALI, D. La sémiotique du texte : du discontinu au continu. Paris : L'Harmattan, 2003.

ABLALI, D.; BADIR, S. Analytiques du sensible. Pour Claude Zilberberg. Limoges: Lambert-Lucas, 2009.

ARRIVE, M.; COQUET, J.-C. Sémiotique en jeu. A partir et autour de l'œuvre d'A. J. Greimas. Paris; Amsterdam; Philadelphia: Hadès-Benjamins, 1987. 
BADIR, S. Épistémologie sémiotique. La théorie du langage de Louis Hjelmslev. Paris: Honoré Champion, 2014.

BEIVIDAS, W. La Sémiotique de Greimas. Une épistémologie (discursive) immanente. Semiotica Journal of the International Association for Semiotic Studies / Revue de l'Association Internationale de Sémiotique. BRODEN, T. (Org.). [Número especial em homenagem ao centenário do nascimento de A. J. Greimas], 2017 (no prelo).

A Semiologia de Saussure como Epistemologia do Conhecimento. Revista Estudos da Linguagem, Belo Horizonte, n. xx, p. x-y, 2015a (no prelo).

A teoria da linguagem de Hjelmslev: uma epistemologia imanente do conhecimento. ESSE - Estudos Semióticos, São Paulo, n. xx, p. X-z, 2015b (no prelo).

. Una epistemologia discursiva en construcción: la teoria semiótica inmanente entre la percepción y la semiocepción. La inmanencia en cuestión I. Tópicos del Seminario. Revista de Semiótica, Puebla (México), n. 31, p. 139-159, 2014.

. Sur l'épistémologie du Résumé: pas de philosophie sans linguistique. Janus Quaderni del circolo glossematico. v. 1, p. 163-175, 2013.

. Inconsciente \& Sentido. Ensaios de interface: psicanálise, linguística, semiótica. São Paulo: AnnaBlume, 2009.

. Reflexões sobre o conceito de imanência em semiótica. Por uma epistemologia discursiva. CASA. Cadernos de Semiótica Aplicada, Araraquara, v. 6, p. 1-13, 2008.

. Inconsciente et verbum. Psicanálise, Semiótica, Ciência, Estrutura. São Paulo: Humanitas, 2001. 
BENVEnISTE, E. Problemas de Linguística Geral II. Campinas: Pontes, 1989.

. Problemas de Linguística Geral I. 3. ed. Campinas: Unicamp, 1991.

COQUET, J. C. Phusis et Logos. Une phénoménologie du langage. Vincennes: PUV, 2007. 1997.

La quête du sens. Le langage en question. Paris: PUF, Réalité et principe d'immanence. Langages, Paris, v. 25, n. 103, p. 23-35, 1991.

FONTANILLE, J. Pratiques sémiotiques. Paris: PUF, 2008a.

. Práticas Semióticas. Imanência e Pertinência, eficiência e otimização. In DINIS, M. L. V. P.; PORTELA, J. C. (Org.). Semiótica e Mídia. Textos, Práticas, Estratégias. Bauru: UNESP-FAAC, 2008b. p. 17-76.

GREIMAS, A. J. Sobre o Sentido II. Tradução de D. F. da Cruz. São Paulo: EDUSP, 2014.

L'énonciation. Une posture épistémologique. Significação. Revista Brasileira de Semiótica, Ribeirão Preto, n. 1, p. 9-25, 1974.

. Sémantique structurale. Recherche de méthode. Paris: Larousse, 1966.

. L'actualité du saussurisme. Le français moderne, Paris, n. 24, p. 191-203, 1956.

GREIMAS, A. J.; COURTES, J. Dictionnaire raisonné de la théorie du langage. Paris: HACHETTE, 1979.

GREIMAS, A. J. ; FONTANILLE, J. Sémiotique des passions. Des états de choses aux états d'âme. Paris: Seuil, 1991. 
HJELMSLEV, L. Prolegômenos a uma Teoria da Linguagem. São Paulo: Perspectiva, 2003.

Nouveaux essais. Paris: PUF, 1985.

- Résumé of a theory of language. Copenhague: Naturmetodens Sproginstitut, 1975.

Prolégomènes à une théorie du langage. Paris: Minuit, 1971a.

. Essais linguistiques. Paris: Minuit, 1971b.

. Le langage. Paris: Minuit, 1966.

MERLEAU-PONTY, M. Le primat de la perception et ses conséquences philosophiques. Paris : Éditions Verdier, 1996.

PARRET, H. La sémiotique de Zilberberg ou le rêve d'un alchimiste. In ABLALI, D. ; BADIR, S. (Org.). Analytiques du sensible. Pour Claude Zilberberg. Limoges: Lambert-Lucas, 2009.

ZILBERBERG, C. ¿ Un par incierto ? Tópicos del Seminario. Revista de Semiótica, Puebla (México), n. 31, p. 195-208, 2014.

. La structure tensive. Liège: PUL. Colléction SIGILLA, 2012.

. Elementos de Semiótica Tensiva. São Paulo: Ateliê Editorial, 2011.

. Razão e poética do sentido. São Paulo: EDUSP, 2006.

. Forme, fonction, affect. In Louis Hjelmslev a cent'anni dalla nascita. Padoua : Imprimitur, 2001. p. 79-100.

. Ensaios sobre semiótica tensiva. Lima: Universidad de Lima/Fondo de Cultura Económica, 1994. 
Waldir BEIVIDAS

Essais sur les modalités tensives. Amsterdam: John Benjamins, 1981.

ZINNA, A.; MORENO, M. L. (Org.). La inmanencia en cuestión. Tópicos del Seminario. Revista de Semiótica, Puebla (México), n. 31, 2014.

Artigo recebido em março de 2015 e aprovado em junho de 2015.

Disponível em: http://seer.fclar.unesp.br/casa 